\title{
ESPAÇAMENTOS ENTRE FILEIRAS E ENTRE PLANTAS NA PRODUÇÃO DA MANDIOQUINHA-SALSA 'BRANCA'
}

\author{
Spaces between rows and plants on yield of 'Branca" Peruvian carrot \\ João Dimas Graciano ${ }^{1}$, Néstor Antonio Heredia Zárate², Maria do Carmo Vieira², \\ Yara Brito Chaim Jardim Rosa ${ }^{2}$, Maria Aparecida Nogueira Sediyama ${ }^{3}$
}

\begin{abstract}
RESUMO
Conduziu-se este trabalho, com o objetivo de avaliar a produtividade, a renda bruta e a composição bromatológica dos diferentes órgãos da planta da mandioquinha-salsa 'Branca', cultivada em dois espaçamentos entre fileiras dentro do canteiro (50 cm e $60 \mathrm{~cm})$ e três espaçamentos entre plantas $(15,20$ e $25 \mathrm{~cm}$ entre plantas). A colheita foi efetuada aos 238 dias após o plantio. As plantas que foram cultivadas com espaçamento de $25 \mathrm{~cm}$ dentro da fileira, independente do espaçamento entre fileiras, apresentaram maior produção de massa fresca $\left(52,16 \mathrm{t} \mathrm{ha}^{-1}\right)$ e seca $\left(5,43 \mathrm{t} \mathrm{ha}^{-1}\right)$ de folhas. Por outro lado, as cultivadas sob $20 \mathrm{~cm}$ entre plantas, independente do espaçamento entre fileiras, resultaram em maiores massas frescas e secas, respectivamente, de $0,62 \mathrm{t} \mathrm{ha}^{-1} \mathrm{e}_{0,24 \mathrm{t}^{-1}}$ de rebentos, $1,08 \mathrm{t} \mathrm{ha}^{-1}$ e $0,36 \mathrm{tha}^{-1}$ de coroas e 15,14 e 2,36 $\mathrm{t} \mathrm{ha}^{-1}$ de raízes comercializáveis, em relação às produções das plantas sob $25 \mathrm{~cm}$. Pelos valores obtidos com os cálculos relativos à renda bruta conclui-se que o produtor de mandioquinha-salsa pode cultivar o clone Branca, utilizando espaçamentos de $50 \mathrm{~cm}$ ou $60 \mathrm{~cm}$ entre fileiras dentro do canteiro e $20 \mathrm{~cm}$ entre plantas dentro das fileiras, o que lhe permitiria obter renda bruta de $\mathrm{R} \$ 83.940,00 \mathrm{ha}^{-1}$ ou $\mathrm{R} \$ 83.124,00 \mathrm{ha}^{-1}$, respectivamente. Os altos teores de resíduos minerais, proteínas, lipídios, carboidratos, fibras e valor calórico total dos órgãos das plantas indicam a possibilidade de uso da mandioquinha-salsa para consumo humano e na alimentação animal.
\end{abstract}

Termos para indexação: Arracacia xanthorrhiza, arranjo de plantas, renda, valor nutritivo.

\section{ABSTRACT}

The aim of this work was to evaluate the yield, income and chemical characteristics of the different organs of 'Branca' Peruvian carrot which was cultivated in two spaces among rows of plants per plot $(50 \mathrm{~cm}$ and $60 \mathrm{~cm})$ and three spaces among plants (15, 20 and $25 \mathrm{~cm}$ among plants). Harvest was done 238 days after planting. Plants which were cultivated with spaces of $25 \mathrm{~cm}$

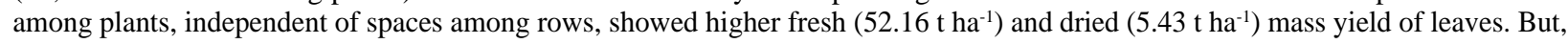
on the other hand, those which were cultivated under spaces of $20 \mathrm{~cm}$ among plants, independent of spaces among rows, resulted in more

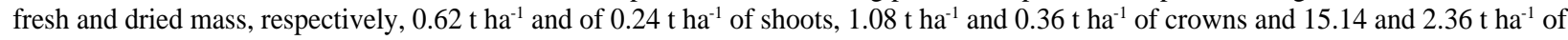
commercial roots, in relation to yields of plants under $25 \mathrm{~cm}$. From the values obtained with calculus concerning to gross income one allowed to conclude that Peruvian carrot producer can cultivate 'Branca' clone using spaces of $50 \mathrm{~cm}$ or $60 \mathrm{~cm}$ among rows in plots and $20 \mathrm{~cm}$ between plants in rows, what allowed producers to obtain gross income of $\mathrm{R} \$ 83,940.00$ or $\mathrm{R} \$ 83,124.00$, respectively. The highest contents of mineral residues, proteins, lipids, carbohydrates, fibers and total caloric value of plant organs indicate the possibility of using it for human consumption and for animal feeding.

Index terms: Arracacia xanthorrhiza, plant arrangement, income, nutritive value.

(Recebido em 5 de junho de 2006 e aprovado em 22 de maio de 2007)

\section{INTRODUÇÃO}

A planta de mandioquinha-salsa (Arracacia xanthorrhiza Bancroft) é rústica e em algumas localidades do Brasil pode ser plantada o ano todo e esperar no solo por melhores preços, com colheitas parciais. Seu produto mais valioso são as raízes, com amido de fácil digestibilidade, de valor nutritivo elevado, ricas em fósforo, cálcio, ferro e vitaminas do complexo B. As folhas servem para texturização e, portanto, para alimentação de animais monogástricos. A planta como um todo, tem sido destinada ao arraçoamento animal na Colômbia e Equador, considerados seus países de origem (VIEIRA, 1995). Apesar de todas essas características favoráveis, o cultivo e a pesquisa da mandioquinha-salsa ainda estão restritos a algumas regiões do Brasil.

\footnotetext{
'Doutor, Bacharel em Zootecnia - Faculdade de Ciências Agrárias/FCA - Universidade Federal da Grande Dourados/UFCG - Rodovia Dourados/Itahum, Km 12, Cidade Universitária - Cx. P. 533 - 79804-970 - Dourados, MS - jdimas@ufgd.edu.br

'Engenheiros Agrônomos, Doutores - Faculdade de Ciências Agrárias/FCA - Universidade Federal da Grande Dourados/UFCG - Rodovia Dourados/Itahum, Km 12, Cidade Universitária - Cx. P. 533 - 79804-970 - Dourados, MS - nahz@terra.com.br; vieiracm@terra.com.br; yararosa@ufgd.edu.br ${ }^{4}$ Engenheira Agrônoma, Doutora - Centro Tecnológico da Zona da Mata - EPAMIG - Vila Gianetti, 46, Campus Universitário da UFV - Cx. P. 216 - $36570-000$ Viçosa, MG - marians@epamig.ufv.br
} 
No Brasil, a mandioquinha-salsa é cultivada principalmente nas regiões Centro-Oeste e Sul, em pequenas áreas, com pouco uso de insumos e mão-deobra familiar. A área de plantio de mandioquinha-salsa é de aproximadamente 16.000 ha, sendo o Paraná e Minas Gerais os principais Estados produtores, com 7.633 ha e 6.000 ha, respectivamente. O Estado de São Paulo contribui apenas com 750 ha. Contudo, o maior volume de mandioquinhasalsa é comercializado no entreposto da CEAGESP (BUENO, 2004).

Apesar de receber denominações conforme o local de cultivo, como, por exemplo, Amarela de Carandaí e Amarela comum, a mandioquinha-salsa cultivada no Brasil restringe-se a poucas cultivares, com características semelhantes e grande uniformidade genética. Há uma cultivar de raízes brancas, cuja planta é bastante vigorosa em relação às de raízes amarelas, de porte alto e expressiva produção de massa verde, chegando a produzir até sete quilos de raízes por plantas. No entanto, seu cultivo é muito restrito, pois suas raízes não têm boa aceitação pelo consumidor, por causa da quase total ausência do aroma característico, do sabor adocicado e mesmo pela sua coloração (SANTOS, 1997).

Sediyama \& Casali (1997) citam que para mandioquinha-salsa, os espaçamentos mais utilizados são de 70 a $80 \mathrm{~cm}$ entre fileiras e de 30 a $40 \mathrm{~cm}$ entre plantas. Nestes espaçamentos, gastam-se, aproximadamente, 42.000 mudas para plantio de um hectare. Considerando que a massa da muda varia entre 3 a $4 \mathrm{~g}$, o gasto é de, aproximadamente, $170 \mathrm{~kg} \mathrm{ha}^{-1} \mathrm{de}$ mudas. Dentre as práticas de cultivo, o espaçamento pode ser manipulado de tal forma a se obter maior número de raízes no tamanho requerido para o mercado ao qual se destina. Em cenoura, por exemplo, os espaçamentos de 8,0 e 12,0 cm entre plantas e três fileiras de plantas no canteiro induziram maior produção de raízes comerciais. Por outro lado, as percentagens de raízes das classes grande, média e pequena foram maiores no espaçamento de 12,0 cm e houve redução de raízes refugos com o aumento do espaçamento (RIBEIRO, 1998).

Com o objetivo de conhecer a produtividade da mandioquinha-salsa 'Amarela de Carandaí', Vieira et al. (1998) avaliaram a resposta ao tamanho de mudas ( grande=26,1 g; médio $=14,2 \mathrm{~g}$; pequeno=8,5 g e muito pequeno $=5,5 \mathrm{~g})$ e populações utilizadas no plantio (20.000; 25.000; 30.000; 35.000 e 40.000 plantas ha $^{-1}$ ). A produção total e as produções dos diferentes componentes das plantas de mandioquinha-salsa tiveram aumentos significativos com o aumento das populações, de 20.000 até 35.000 plantas ha-1 ${ }^{-1}$ exceto para produção de raiz nãocomercializável, que aumentou até 30.000 plantas ha' ${ }^{-1}$.
Como não há recomendação de arranjo de plantas em mandioquinha-salsa para o Brasil, evidencia-se a necessidade de pesquisas sobre o assunto. Em razão disso, objetivou-se com este trabalho avaliar a capacidade produtiva da mandioquinha-salsa 'Branca', cultivada sob dois espaçamentos entre fileiras de plantas no canteiro e três espaçamentos entre plantas, visando aumentar a produtividade e a renda do produtor e melhorar a composição bromatológica dos diferentes órgãos da planta.

\section{MATERIAL E MÉTODOS}

O experimento foi desenvolvido em área do Horto de Plantas Medicinais, do Núcleo Experimental de Ciências Agrárias, da Universidade Federal de Mato Grosso do Sul, em Dourados-MS, entre 3 de abril e 27 de novembro de 2003. O solo é do tipo Latossolo Vermelho distroférrico, cujas características químicas foram: 4,9 de $\mathrm{pH}$ em $\mathrm{CaCl}_{2}$; 29,0 $\mathrm{g} \mathrm{dm}^{-3}$ de M.O; 3,3 mg dm${ }^{-3}$ de P; 4,8; 52,5 e 25,2 $\mathrm{mmol}^{\circ}$ $\mathrm{dm}^{-3}$ de $\mathrm{K}, \mathrm{Ca}$ e $\mathrm{Mg}$, respectivamente. O clima da região, segundo a classificação de Köppen, é Mesotérmico Úmido; do tipo Cwa, com temperaturas e precipitações médias anuais variando de $20^{\circ}$ a $24^{\circ} \mathrm{C}$ e de $1250 \mathrm{~mm}$ a 1500 $\mathrm{mm}$, respectivamente.

Foi utilizada a mandioquinha-salsa 'Branca', cultivada em canteiros com duas fileiras de plantas, sob espaçamentos de $50 \mathrm{~cm}$ e $60 \mathrm{~cm}$ entre fileiras simples e três espaçamentos entre plantas $(15,20$ e $25 \mathrm{~cm})$ na fileira, que resultaram nas populações de $87.912 ; 66.000$ e 52.800 plantas $\mathrm{ha}^{-1}$, respectivamente. Os tratamentos foram arranjados como fatorial 2 (espaçamentos entre fileiras) x 3 (espaçamentos entre plantas), no delineamento experimental de blocos casualizados, com quatro repetições. As parcelas tinham área total de 4,5 m² (1,5 m de largura por 3,0 $\mathrm{m}$ de comprimento), sendo que a largura efetiva do canteiro foi $1,08 \mathrm{~m}$.

O terreno foi preparado com trator, duas semanas antes do plantio, com uma aração e uma gradagem e, posteriormente, foram levantados os canteiros com rotoencanteirador. No dia do plantio, no canteiro foram abertos dois sulcos de plantio de $5 \mathrm{~cm}$ de largura e $5 \mathrm{~cm}$ de profundidade. As mudas para o plantio foram obtidas de rebentos de tamanho médio (massa média de 6,5 g) que, após terem sido selecionadas e cortadas horizontalmente na parte basal, foram colocados no fundo dos sulcos, com os ápices para cima e cobertas com solo. As irrigações foram feitas utilizando o sistema de aspersão, sendo que na fase inicial, até as plantas apresentarem em torno de 10 $\mathrm{cm}$ de altura, os turnos de rega foram diários e, posteriormente, a cada dois dias. Durante o ciclo da cultura não foi feita nenhuma adubação e calagem para corrigir o 
solo. Foram feitas capinas com enxada, entre os canteiros, e manualmente, nos canteiros. Não houve infestações de pragas ou infecções de doenças.

Efetuou-se a colheita aos 238 dias após o plantio, quando as plantas apresentavam mais de $50 \%$ de senescência da parte foliar, época em que avaliaram-se as alturas das plantas; as produções de massas frescas e secas de folhas, rebentos, coroas, raízes comercializáveis (massa maior que $40 \mathrm{~g}$ ) e raízes não comercializáveis (menores que $40 \mathrm{~g}$ ). Foram realizadas as estimativas da renda bruta, considerando as produções de massa fresca de raízes de tamanho comercializável vezes o preço pago ao agricultor por cada quilograma de raízes comerciais de mandioquinha-salsa $\left(\mathrm{R} \$ 1,20 \mathrm{~kg}^{-1}\right)$. Amostras de massas secas dos diferentes componentes das plantas foram enviadas ao Laboratório de Tecnologia de Alimentos da UFMS, Campo Grande - MS, para realização das análises bromatológicas. Os dados foram submetidos à análise de variância e, quando verificou-se significância pelo teste $\mathrm{F}$, aplicou-se o teste de Tukey, ao nível de 5\% de probabilidade (RIBEIRO JÚNIOR, 2001).

\section{RESULTADOS E DISCUSSÃO}

Nenhuma característica avaliada foi influenciada significativamente pela interação espaçamentos entre fileiras no canteiro e espaçamentos entre plantas dentro da fileira. As produções de massa fresca de raiz comercial (Tabela 1) e de massa seca de coroas (Tabela 2) foram influenciadas significativamente pelos espaçamentos entre plantas. Estudando os espaçamentos de 20, 30, 40 e $50 \mathrm{~cm}$ entre plantas de mandioquinha-salsa 'Amarela de Carandaí', Carmo et al. (1996) também observaram maior produção de raízes totais e comercializáveis sob $20 \mathrm{~cm}$ e recomendaram a população de 62.500 plantas $\mathrm{ha}^{-1}$, semelhante à que resultou em maiores produções neste trabalho.

As outras características avaliadas, tais como altura de plantas $(59,10 \mathrm{~cm})$, massa fresca de folhas $\left(47,90 \mathrm{t} \mathrm{ha}^{-1}\right)$, rebento $\left(20,35 \mathrm{t} \mathrm{ha}^{-1}\right)$, coroa $\left(8,68 \mathrm{t} \mathrm{ha}^{-1}\right)$ e raízes não comercializáveis $\left(11,09 \mathrm{t} \mathrm{ha}^{-1}\right)$ não foram influenciadas pelos tratamentos. Esses resultados mostram que, provavelmente, houve modificações na plasticidade fisiológica da planta para adaptar-se a essas condições do ambiente. Também mostram que não se chegou à pressão populacional que diminuísse as capacidades produtivas totais das plantas da mandioquinha-salsa 'Branca' em conseqüência da competição por fatores de crescimento, tais como luz, nutrientes e água, o que poderia resultar em decréscimo da produção (MARSCHNER, 1995), tal como Heredia Zárate (1988) observou em taro (Colocasia esculenta (L.) Schott). Isso porque, conforme Vieira et al. (1996), ao contrário do que ocorre com os sistemas radiculares em geral, que são pouco favorecidos em termos de distribuição de nutrientes pelas plantas, as raízes reservantes de mandioquinha-salsa, uma vez presentes, funcionam como drenos preferenciais.

Tabela 1 - Altura média de plantas e produção de massa fresca de folhas, rebentos, coroas e raízes, comercializáveis e não comercializáveis das plantas de mandioquinha-salsa 'Branca' cultivadas em dois espaçamentos entre fileiras e três espaçamentos entre plantas. UFMS, Dourados-MS, 2003.

\begin{tabular}{|c|c|c|c|c|c|c|}
\hline \multirow{3}{*}{$\begin{array}{l}\text { Espaçamento } \\
(\mathrm{cm})\end{array}$} & \multirow{3}{*}{$\begin{array}{l}\text { Altura da } \\
\text { planta } \\
\text { (cm) }\end{array}$} & \multicolumn{5}{|c|}{ Produção $\left(\mathrm{t} \mathrm{ha}^{-1}\right)$} \\
\hline & & \multirow[t]{2}{*}{ Folhas } & \multirow[t]{2}{*}{ Rebento } & \multirow[t]{2}{*}{ Coroa } & \multicolumn{2}{|c|}{ Raízes } \\
\hline & & & & & Comercial & Não Comercial \\
\hline \multicolumn{7}{|l|}{ Entre fileiras } \\
\hline 50 & 58,82 & 46,77 & 19,32 & 8,12 & 55,78 & 11,67 \\
\hline 60 & 59,39 & 49,04 & 21,38 & 9,24 & 64,70 & 10,51 \\
\hline \multicolumn{7}{|l|}{ Entre plantas } \\
\hline 15 & 57,05 & 46,89 & 19,88 & 8,98 & $56,62 \mathrm{ab}$ & 13,11 \\
\hline 20 & 61,68 & 44,65 & 20,90 & 9,07 & $69,61 \mathrm{a}$ & 8,26 \\
\hline 25 & 58,59 & 52,16 & 20,28 & 7,99 & 54,47 b & 11,89 \\
\hline C.V. (\%) & 6,30 & 35,56 & 22,82 & 18,05 & 19,45 & 41,72 \\
\hline
\end{tabular}

Médias seguidas pela mesma letra, nas colunas, dentro de cada fator, não diferem entre si pelo Teste Tukey, a 5\% de probabilidade. 
Apesar da falta de significância entre os tratamentos, para a maioria de características avaliadas, observou-se que as plantas cultivadas no espaçamento de $25 \mathrm{~cm}$ dentro da fileira apresentaram maiores produções de massas fresca $\left(52,16 \mathrm{t} \mathrm{ha}^{-1}\right)$ e seca $\left(5,43 \mathrm{t} \mathrm{ha}^{-1}\right)$ de folhas. Em compensação, apresentaram menores massas fresca (Tabela 1) e seca (Tabela 2), respectivamente, para rebentos $\left(0,62 \mathrm{t} \mathrm{ha}^{-1}\right.$ e $\left.0,24 \mathrm{t} \mathrm{ha}^{-1}\right)$, coroas $\left(1,08 \mathrm{tha}^{-1}\right.$ e 0,36 $\mathrm{t}$ ha $\left.{ }^{-1}\right)$ e de raízes comercializáveis $\left(15,14\right.$ e $\left.2,36 \mathrm{t} \mathrm{ha}^{-1}\right)$, em relação às produções obtidas no espaçamento de $20 \mathrm{~cm}$ entre plantas. Os resultados deste trabalho são coerentes com as citações de Casali et al. (1984), de que as plantas que apresentam crescimento exuberante podem não produzir muito bem, uma vez que podem ter que gastar muitos fotoassimilados com a manutenção da parte aérea e, assim, terem retardadas a maturidade e o início do processo de senescência das folhas mais velhas, com atraso na translocação dos fotoassimilados de reserva para as raízes (VIEIRA, 1995; VIEIRA et al., 1998). Por outro lado, são contrários aos dados de Bustamante (1988), Câmara et al. (1985) e Vieira (1995), obtidos na mandioquinha-salsa 'Amarela de Carandaí', os quais observaram correlação positiva entre a produção da parte subterrânea e da parte aérea, ou seja, as plantas de mandioquinha-salsa mais altas, que são mais exuberantes e possuem maior área foliar, produziram maior quantidade de raízes comerciais.

Pelos valores obtidos com as estimativas da renda bruta (Tabela 3) concluiu-se que o produtor de mandioquinha-salsa pode cultivar o clone Branca utilizando espaçamentos de $50 \mathrm{~cm}$ ou $60 \mathrm{~cm}$ entre fileiras dentro do canteiro e $20 \mathrm{~cm}$ entre plantas dentro das fileiras, o que lhe permitiria obter renda bruta de $\mathrm{R} \$$ $83.940,00 \mathrm{ha}^{-1}$ ou $\mathrm{R} \$ 83.124,00 \mathrm{ha}^{-1}$, respectivamente. A estimativa da renda bruta obtida no tratamento $50 \mathrm{~cm}$ entre fileiras e $20 \mathrm{~cm}$ entre plantas foi $62,07 \%$ maior ( $R \$$ $32.148,00$ ) do que no cultivo sob $50 \mathrm{~cm}$ entre fileiras e 25 $\mathrm{cm}$ entre plantas, tratamento este com a menor produção (Tabela 3). Esses resultados confirmam que a maximização da produção depende da capacidade de suporte do meio e do sistema de produção adotado (BÜLL, 1993).

Tabela 2 - Produção de massa seca de folhas, rebentos, coroas e raízes, comercializáveis e não comercializáveis das plantas de mandioquinha-salsa 'Branca' cultivadas em dois espaçamentos entre fileiras e três espaçamentos entre plantas. UFMS, Dourados-MS, 2003.

\begin{tabular}{cccccc}
\hline \multirow{2}{*}{$\begin{array}{c}\text { Espaçamento } \\
(\mathrm{cm})\end{array}$} & Folhas & Rebento & Coroa & \multicolumn{3}{c}{ Raízes } \\
\cline { 5 - 6 } & & & & Comercial & Não Comercial \\
\hline Entre fileiras & & & & 11,16 & 2,44 \\
\hline 50 & 4,78 & 2,28 & 1,49 & 12,97 & 2,27 \\
\hline 60 & 5,09 & 2,55 & 1,61 & & 2,85 \\
\hline Entre plantas & & & & 11,60 & 1,80 \\
\hline 15 & 4,88 & 2,39 & $1,63 \mathrm{a}$ & 13,48 & 2,41 \\
\hline 20 & 4,51 & 2,55 & $1,70 \mathrm{a}$ & 11,12 & 36,99 \\
\hline C.V. (\%) & 5,43 & 2,31 & $1,34 \mathrm{~b}$ & 19,56 & \\
\hline
\end{tabular}

Médias seguidas pela mesma letra, nas colunas, dentro de cada fator, não diferem entre si pelo Teste Tukey, a 5\% de probabilidade. 
Tabela 3 - Estimativas de Renda bruta das raízes comercializáveis de mandioquinha-salsa 'Branca' cultivadas sob dois espaçamentos entre fileiras e três espaçamentos entre plantas. UFMS, Dourados-MS, 2003.

\begin{tabular}{cccc}
\hline \multicolumn{2}{c}{ Espaçamento $(\mathrm{cm})$} & $\begin{array}{l}\text { Produção } \\
\left(\mathrm{kg} \mathrm{ha}^{-1}\right)^{*}\end{array}$ & $\begin{array}{c}\text { Renda bruta } \\
(\mathrm{R} \$)\end{array}$ \\
\hline Entre fileiras & Entre plantas & $54.230,00$ & $65.076,00$ \\
\multirow{2}{*}{50} & 20 & $69.950,00$ & $83.940,00$ \\
& 25 & $43.160,00$ & $51.792,00$ \\
\hline \multirow{2}{*}{60} & 15 & $59.010,00$ & $70.812,00$ \\
& 20 & $69.270,00$ & $83.124,00$ \\
& 25 & $65.790,00$ & $78.948,00$ \\
\hline
\end{tabular}

*Preço pago ao produtor de mandioquinha-salsa ‘Amarela de Carandaí', em Dourados-MS, em outubro de 2004, R\$1,20 kg-1.

A composição bromatológica das plantas da mandioquinha-salsa 'Branca' variou mais em função do componente das plantas que dos espaçamentos utilizados (Tabela 4). Os teores de resíduos minerais, proteínas e carboidratos foram considerados bons, quando comparados com os apresentados por alguns autores. Pereira (1997) cita, para as raízes de mandioquinha-salsa, média de 74\% de umidade, 24,91 $\%$ de carboidratos, $0,96 \%$ de proteínas e 104 calorias por 100 gramas do material seco, valores esses inferiores aos obtidos neste trabalho nas raízes, coroas e rebentos e apenas comparáveis aos obtidos nas folhas. Diferenças semelhantes ocorreram ao comparar com Luengo et al. (2000), que relataram que a mandioquinha-salsa tem $76,70 \%$ de água e 125,5 calorias em 100 gramas de matéria fresca de raízes. As raízes de tamanho médio a extra e, ocasionalmente, as pequenas, que são comercializadas e consumidas, representaram apenas o uso de 40,60\% de massa fresca das plantas. As folhas, rebentos, coroas e raízes nãocomerciais representaram 59,40\% das plantas, que são os resíduos descartáveis (HEREDIA ZÁRATE \& VIEIRA, 1998). Estes possuem altos valores nutritivos (proteínas, lipídios, carboidratos totais, valores calóricos totais e resíduos minerais fixos), poderiam ser transformados em massas secas e serem utilizadas ou comercializadas como ingredientes alternativos para alimentação animal (HEREDIA ZÁRATE \& VIEIRA, 1998; VIEIRA et al., 1999). Essa hipótese é justificada pelo fato de a mandioquinha-salsa ter composição equivalente à do milho e sorgo, alimentos usualmente componentes das rações. Isso é confirmado por Scheuermann (1998) que, trabalhando com frangos de corte, relatou que o milho contém $3.390 \mathrm{Kcal} \mathrm{kg}^{-1}$ de energia metabolizável; $7,60 \%$ de proteína bruta; $2,17 \%$ de fibra bruta e $3,80 \%$ de extrato etéreo e que o sorgo contém $3.290 \mathrm{Kcal} \mathrm{kg}^{-1}$ de energia metabolizável; 8,00\% de proteína bruta; $2,70 \%$ de fibra bruta e $2,70 \%$ de extrato etéreo. Além disso, considerando o alto custo do milho e do sorgo e que os resíduos da mandioquinha-salsa são descartados, esses resíduos poderiam então ser usados na ração animal. 


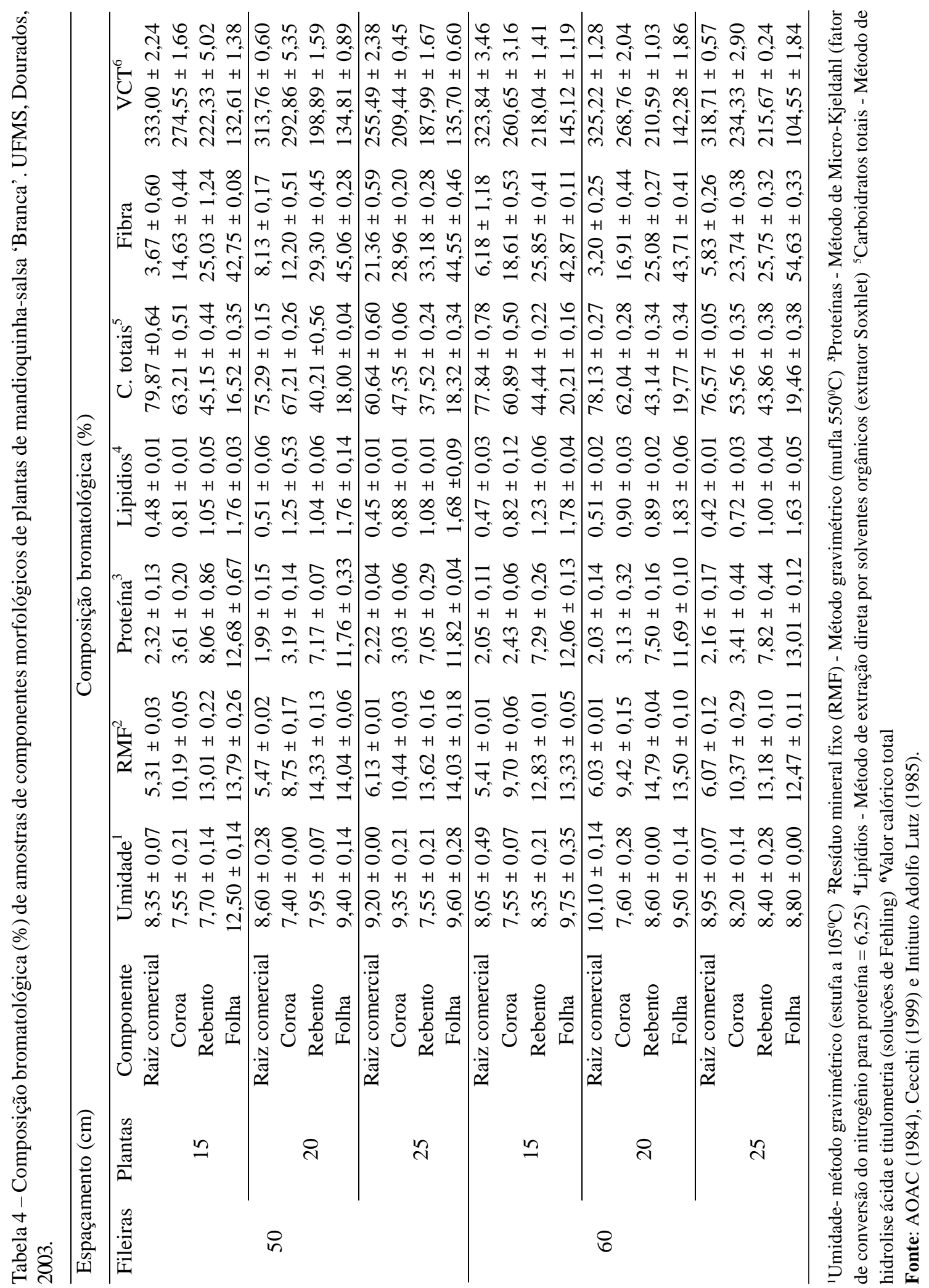




\section{CONCLUSÕES}

Os resultados, nas condições do experimento, permitiram concluir que para obter maior produtividade de raízes comerciais e maior renda bruta no cultivo da mandioquinha-salsa 'Branca' deve-se recomendar o plantio em canteiros, nos espaçamentos de $50 \mathrm{~cm}$ ou $60 \mathrm{~cm}$ entre fileiras de plantas e 15 e $20 \mathrm{~cm}$ entre plantas dentro da fileira. $\mathrm{O}$ arranjo de plantas não interferiu nas características bromatológicas das diferentes partes da planta. Os resíduos descartáveis das plantas de mandioquinha-salsa 'Branca' podem ser testados na alimentação de animais, devido aos seus altos valores nutritivos.

\section{AGRADECIMENTOS}

Ao CNPq, pelas bolsas concedidas e à FUNDECTMS, pelo apoio financeiro.

\section{REFERÊNCIAS BIBLIOGRÁFICAS}

ASSOCIATION OF OFFICIAL ANALYTICAL CHEMISTS. Official methods of analysis of Association of Official Analytical Chemists. Washington, 1984. 988 p. (Técnica, 47021).

BÜLL, L. T. Cultura do milho: fatores que afetam a produtividade. Piracicaba: Potafós, 1993. 301 p.

BUENO, S. C. S. Produção de mandioquinha-salsa (Arracacia xanthorrhiza Bancroft) utilizando diferentes tipos de propágulos. 2004. 93 f. Tese (Doutorado em Agronomia) - Escola Superior de Agricultura Luiz de Queiroz, Universidade de São Paulo, Piracicaba, 2004.

BUSTAMANTE, P. G. Melhoramento de batata-baroa (Arracacia xanthorrhiza Bancroft): I. biologia floral: obtenção e caracterização de novos clones: correlações genéticas. 1988. 94 f. Dissertação (Mestrado em Fitotecnia) - Universidade Federal de Viçosa, Viçosa, 1988.

CÂMARA, F. L. A.; CASALI, V. W. D.; THIÉBAUT, J. T L.; MEDINA, P. V. L. Época de plantio, ciclo e amassamento dos pecíolos da mandioquinha-salsa. Horticultura Brasileira, Brasília, v. 3, n. 2, p. 25-28, 1985.

CARMO, C. A. S.; FORNAZIER, M. J.; SANTOS, F. F. Densidade populacional de plantas de mandioquinha-salsa (Arracacia xanthorrhiza). Horticultura Brasileira, Brasília, v. 14, n. 1, p. 78, 1996. Resumo 62.
CASALI, V. W. D.; SEDIYAMA, M. A. N.; CAMPOS, J. $\mathrm{P}$. Métodos culturais da mandioquinha-salsa. Informe Agropecuário, Belo Horizonte, v. 10, n. 120, p. 26-28, 1984.

CECCHI, H. M. Fundamentos teóricos e práticos em análise de alimentos. Campinas: Unicamp, 1999. 212 p.

HEREDIA ZÁRATE, N. A. Curvas de crescimento de inhame (Colocasia esculenta (L.) Schott), considerando cinco populações, em solo seco e alagado. 1988. 95 f. Tese (Doutorado em Fitotecnia) - Universidade Federal de Viçosa, Viçosa, 1988.

HEREDIA ZÁRATE, N. A.; VIEIRA, M. C. Produção e uso de hortaliças amídicas para consumo humano e para alimentação de frangos de corte. In: SIMPÓSIO INTERNACIONAL SOBRE AGRICULTURA SUSTENTABLE, 1., 1998, Pedro Juan Caballero. Palestra... Pedro Juan Caballero: [s.n.], 1998.

INSTITUTO ADOLFO LUTZ. Normas analíticas do Instituto Adolfo Lutz: métodos químicos e físicos para análise de alimentos. São Paulo, 1985. 533 p.

LUENGO, R. T. A.; PARMAGNANI, R. M.; PARENTE, M. R.; LIMA, M. F. B. F. Tabela de composição nutricional de hortaliças. Brasília, DF: Embrapa, 2000.

MARSCHNER, H. Mineral nutrition of higher plants. London: Academic, 1995. 902 p.

PEREIRA, A. S. Valor nutritivo da mandioquinha. Informe Agropecuário, Belo Horizonte, v. 190, n. 19, p. 11-12, 1997.

RIBEIRO JUNIOR, J. I. Análise estatística no SAEG. Viçosa: UFV, 2001. 301 p.

RIBEIRO, R. A. Produção e conservação da cenoura (Daucus carota L., Apiaceae) cultivar Brasília, considerando espaçamentos e armazenamento de raízes e plantas. 1998. 38 f. Dissertação (Mestrado em Agronomia) - Universidade Federal de Mato Grosso do Sul, Dourados, 1998.

SANTOS, F. F. dos. A cultura da mandioquinha-salsa no Brasil. Informe Agropecuário, Belo Horizonte, v. 19, n. 190, p. 5-7, 1997 
SCHEUERMANN, N. Utilização do sorgo em rações para frangos de corte. Concórdia: Embrapa-CNPSA, 1998. 3 p. (Instrução Técnica).

SEDIYAMA, M. A.; CASALI, V. W. D. Propagação vegetativa da mandioquinha-salsa. Informe Agropecuário, Belo Horizonte, v. 19, n. 190, p. 24-27, 1997.

VIEIRA, M. C. Avaliação do crescimento, da produção de clones e efeito de resíduo orgânico e de fósforo em mandioquinha-salsa no Estado de Mato Grosso do Sul. 1995. 146 f. Tese (Doutorado em Fitotecnia) - Universidade Federal de Viçosa, Viçosa, 1995.

VIEIRA, M. C.; HEREDIA ZÁRATE, N. A.; GRACIANO, J. D.; RIBEIRO, R. Uso de matéria seca de cará e de mandioquinha-salsa substituindo parte do milho na ração para frangos de corte. Horticultura Brasileira, Brasília, v. 17, n. 1, p. 34-38, 1999.

VIEIRA, M. C.; HEREDIA ZÁRATE, N. A.; SIQUEIRA, J. G. de; CASALI, V. W. D. Crescimento e produção de mandioquinha-salsa em função de características das mudas. Horticultura Brasileira, Brasília, v. 14, n. 1, p. 4244, 1996.

VIEIRA, M. C.; HEREDIA ZÁRATE, N. A.; VITORINO, P. F. G. Produção de mandioquinha-salsa em resposta ao tamanho de mudas e populações. In: CONGRESSO BRASILEIRO DE OLERICULTURA, 38., 1998, Petrolina. Resumos... Petrolina: [s.n.], 1998. Resumo 363. 